\title{
Rechallenge of clozapine in a patient with a history of clozapine-induced myocarditis
}

\author{
Buket Koparal $^{\oplus}$, Melike Kucukkarapinar ${ }^{2}$, Irem Ekmekci Ertek ${ }^{2}$ \\ 'Recep Tayyip Erdoğan University Training and Research Hospital, Department of Psychiatry, Rize, Turkey \\ ${ }^{2}$ Gazi University Faculty of Medicine, Department of Psychiatry, Ankara, Turkey
}

\begin{abstract}
Clozapine is the only antipsychotic with proven efficacy in treatment-resistant schizophrenia, but some life-threatening side effects limit its use. Here we report a patient with clozapine-induced myocarditis and successful rechallenge. The patient still uses clozapine and has not developed myocarditis over 36 months of observation. It may be possible to use clozapine even after myocarditis and thus improve symptoms and functionality of schizophrenia patients.
\end{abstract}

Keywords: Clozapine, myocarditis, rechallenge, schizophrenia

\section{INTRODUCTION}

Clozapine is an atypical antipsychotic with a tricyclic dibenzodiazepine structure. It has potent serotonin and noradrenaline antagonist properties as well as binding to D1 and D4 receptors with high affinity and to D2 receptors with weak affinity. It is the only antipsychotic with proven efficacy in treatment-resistant schizophrenia. The low risk of extrapyramidal side effects is one of the most important advantages of clozapine, together with its reducing positive symptoms, negative symptoms, aggression, and the hostility risk. On the other hand, there are rare but potentially fatal side effects such as agranulocytosis, hepatitis, and myocarditis (1).

Myocarditis is an inflammation of heart muscles leading to the impairment of cardiac functions due to myocyte damage. Mostly, it is seen in viral infections and immunologic diseases, but drugs also play a role in its etiology (2).
The risk of developing myocarditis due to clozapine use has been reported at various rates in studies and case reports. The incidence varies between $0.015 \%$ and $0.188 \%(3-5)$. Myocarditis is not dose-dependent and is often seen within the first 2 months of treatment, most often within the first 4 weeks (4). Sufficient knowledge about the mechanism is not yet available, but type 1 hypersensitivity, direct toxic effect, and increased inflammatory cytokine release have been discussed in this area (6). Fever, tachycardia, chest pain, dyspnea, leukocytosis, non-specific electrocardiogram (ECG) changes, and elevated cardiac enzymes (troponin, CK-MB) can be seen, but none of them are pathognomonic (2).

The development of myocarditis due to the use of clozapine can be rapid and fatal. Therefore, it is very important to recognize relevant cases and stop using the medicine after diagnosis. There is no specific therapy for myocarditis; supportive and symptomatic treatment is recommended.

How to cite this article: Koparal B, Kucukkarapinar M, Ekmekci Ertek I. Rechallenge of clozapine in a patient with a history of clozapine-induced myocarditis. Dusunen Adam The Journal of Psychiatry and Neurological Sciences 2019;32:275-278.

Correspondence: Buket Koparal, Recep Tayyip Erdoğan University Training and Research Hospital, Department of Psychiatry, Rize, Turkey 
Information on the resumption of clozapine in cases with clozapine-induced myocarditis is very limited. There are no data on the risk of recurrence of the disease when clozapine is restarted. Although the use of clozapine is not usually recommended in these cases, there are case reports of successful treatment results.

\section{CASE}

A 30-year-old male patient had been followed for 10 years with paranoid schizophrenia. The case, whose symptoms did not improve despite the use of drugs such as haloperidol, amisulpride, quetiapine, and olanzapine in appropriate doses and with adequate duration, was evaluated as treatment-resistant schizophrenia, and we decided to start clozapine. Before beginning the treatment, the patient's hemogram $(\mathrm{CBC})$, liver functions (LF), kidney functions (KF), and electrocardiogram (ECG) were examined. All laboratory results and the ECG were normal. Clozapine was started with $25 \mathrm{mg} /$ day; on day 16 , with a clozapine dose of $350 \mathrm{mg} /$ day, the patient complained of chest pain, palpitation, shaking, cold, and diarrhea. He had a fever of $38.2^{\circ} \mathrm{C}$ and tachypnea (respiratory rate: $20 \mathrm{~min}-1$ ). He had no tachycardia and his blood pressure was normal $(120 / 80 \mathrm{mmHg})$. There were no pathological findings in the physical examination. At first, CBC, LF, KF, cardiac enzymes, and ECG were normal. Troponin protein levels, erythrocyte sedimentation rate, and C-reactive protein levels were elevated to $0.7 \mathrm{ng} / \mathrm{ml}$ (reference range: $0-0.5 \mathrm{ng} / \mathrm{ml}$ ), $35 \mathrm{~mm} / \mathrm{h}$ (reference range: $0-10 \mathrm{~mm} / \mathrm{h}$ ), and $259 \mathrm{mg} / \mathrm{dl}$ (reference range: $0-0.7 \mathrm{mg} / \mathrm{dl}$ ), respectively. The patient was referred to cardiology for consultation. The echocardiogram (ECHO) showed decompensated heart failure with a decreased ejection fraction (EF) (35\%; reference range: $50-70 \%)$. The consultant cardiologist diagnosed myocarditis secondary to clozapine as no other confounding comorbidity was identified. No concomitant drug use or viral infection was detected. The patient was admitted to the cardiac intensive care unit. Clozapine was ceased and rapid titration of quetiapine $600 \mathrm{mg} /$ day was started because the patient had paranoid delusions and was also agitated. He needed antipsychotic medication as well as some sedation. No specific treatment was required. Three days later, the cardiac damage profile returned to normal and the $\mathrm{EF}$ increased to $60 \%$. The patient was discharged from the cardiology unit and 12 days later was readmitted to the psychiatry ward. During his stay in psychiatry, quetiapine was increased to $1200 \mathrm{mg}$, mainly because in treatment-resistant schizophrenia, high doses of antipsychotics are recommended. During follow-up, there was no improvement in his psychotic symptoms; thus amisulpride was added because of its high D2-receptor affinity and increased to $1200 \mathrm{mg}$. After almost two months, the patient was discharged from the hospital with partial remission.

At the 7-month follow-up evaluation, the patient was hospitalized again due to acute psychotic exacerbation, as he had stopped taking his medication because of his paranoid delusions and auditory hallucinations. He believed that his family was trying to poison him. After admission to the psychiatry ward and in consultation with cardiology, the patient's family, and the patient himself, it was decided to restart clozapine. ECHO, ECG, C-reactive protein levels, and cardiac damage profile were controlled before treatment. Clozapine was started with $12.5 \mathrm{mg} /$ day and increased by $12.5 \mathrm{mg}$ every 2 days in the first 2 weeks and then by $12.5 \mathrm{mg} /$ day. CBC, cardiac enzymes, C-reactive protein levels, and ECG were controlled during the first 8 weeks. No cardiac complaints or side effects were observed during this time. The patient was discharged from hospital after 8 weeks. His disorganized behavior, paranoid delusions, and hallucinations decreased and his functionality increased over time. Until now, he has used $400 \mathrm{mg} /$ day clozapine for 36 months and has been free of cardiac side effects.

\section{DISCUSSION}

Clozapine-induced myocarditis is a rare but fatal condition. None of the complaints seen in this case, such as fever, tachycardia, chest pain and shortness of breath, were found to be pathognomonic as all these symptoms can be seen in the absence of myocarditis. Cardiac markers such as CK-MB and troponin should be routinely measured in patients when considering myocarditis. Troponin was found to be highly sensitive (89\%) and less specific (35\%) in detecting myocarditis (3). Inflammatory manifestations including CRP, sedimentation rate, and leukocytosis are also used in diagnosis, but none of them is pathognomonic. Definitive diagnosis is made by biopsy. The mechanism by which clozapine causes cardiotoxicity is not exactly known. Peripheral eosinophilia and eosinophilic inclusions in the myocardial biopsy seen in the affected patients suggest an IgE-mediated hypersensitivity 
response. However, the available study results are inconsistent. Compared to other antipsychotics, noradrenalin levels are higher in patients using clozapine. Elevated noradrenalin levels might cause cardiac dysfunction (4). It is known that clozapine is metabolized by microsomal enzymes in the liver. Cytochrome P450 1A2/1A3 enzyme deficiencies can lead to high plasma levels of clozapine and therefore may also be associated with myocarditis and sudden death $(5,6)$.

Generally, it has been thought that the progression of myocarditis is independent from clozapine dosage. In a study with 105 patients, participants taking $500 \mathrm{mg}$ or less clozapine in the first 9 days of treatment had a lower risk of myocarditis than patients taking $920 \mathrm{mg}$ or more, suggesting a connection between rapid dose titration and myocarditis development (5). In the case presented, myocarditis developed in the $3 \mathrm{rd}$ week of treatment with a $25 \mathrm{mg} /$ day titration, and a total dose of 2,315 mg clozapine had been used.

One study found no significant difference in age, gender, smoking cessation, recent clozapine dosage, and additional drug use between survivors and fatalities of clozapine-induced myocarditis (7). In our case, no cardiac risk factor such as hypertension, family history of heart disease, or smoking was present. When clozapine was restarted, the patient was smoking half a pack of cigarettes per day.

The reintroduction of clozapine after the development of clozapine-induced myocarditis is controversial. Often, restarting clozapine is not recommended. However, there are also studies where clozapine was resumed successfully (8-11). Most publications supporting this rechallenge come from Australia. In a paper from 2011, Ronaldson et al. (12) advised to follow patients who restart clozapine for weekly cardiac enzyme tests and CRP for the first 4 weeks and to stop the use of the drug in case of any findings such as troponin levels $>2$ ULN, CRP $>100$, or cardiac dysfunction with physical complaints seen in echocardiography.

The decision for restarting clozapine should be discussed with the patient, his or her relatives, and a cardiologist. In our case, after carrying out the necessary interviews and receiving written consent, the patient was readmitted to hospital for close observation. Cardiac functions and routine tests were evaluated, and after finding normal results, treatment started with 12.5 $\mathrm{mg}$ of clozapine, titrated slowly by $12.5 \mathrm{mg} / 2$ days. Dose titration was planned at a rate of $12.5 \mathrm{mg} /$ day for a longer period. The patient was observed closely for cardiac and other adverse effects during the first 8 weeks; weekly cardiac enzyme levels, ECG, ECHO, and $\mathrm{CBC}$ were obtained. The patient's monitoring protocol was regulated in line with suggestions found in the literature (12).

This case report is a successful example of the reintroduction of clozapine in a patient who had previously developed clozapine-induced myocarditis $(8,9,13,14)$. In this case, slow titration was performed different from the first clozapine use, which may have prevented another onset of myocarditis. Relatively rapid titration may trigger myocarditis in susceptible individuals (5). Further studies are needed to determine the risk factors for this course.

\begin{tabular}{|l|l|l|}
\hline \multirow{4}{*}{ Contribution Categories } & Author Initials \\
\hline \multirow{4}{*}{ Category 1} & Concept/Design & \\
\cline { 2 - 3 } & Literature review & M.K., I.E.E. \\
\cline { 2 - 3 } & Data analysis/Interpretation & \\
\cline { 2 - 3 } & Case follow-up (if applicable) & B.K. \\
\hline \multirow{3}{*}{ Category 2} & Drafting manuscript & B.K. \\
\cline { 2 - 3 } & Critical revision of manuscript & M.K., I.E.E. \\
\hline \multirow{2}{*}{ Category 3} & Final approval and accountability & I.E.E., M.K., B.K. \\
\hline \multirow{3}{*}{ Other } & Technical or material support & I.E.E. \\
\cline { 2 - 3 } & Supervision & \\
\hline
\end{tabular}

Informed Consent: Written informed consent was obtained from the patients.

Peer-review: Externally peer-reviewed.

Conflict of Interest: The authors declared no conflicts of interest.

Financial Disclosure: The authors declared no financial support.

\section{REFERENCES}

1. De Berardis D, Serroni N, Campanella D, Olivieri L, Ferri F, Carano A, Cavuto M, Martinotti G, Cicconetti A, Piersanti M, Saverio Moschetta F, Di Giannantonio M. Update on the adverse effects of clozapine: focus on myocarditis. Curr Drug Saf 2012; 7:55-62.[CrossRef]

2. Datta T, Solomon AJ. Clozapine-induced myocarditis. Oxf Med Case Reports 2018; 2018:omx080. [CrossRef]

3. Magnani JW, Dec JW. Myocarditis: Current Trends in Diagnosis and Treatment. Circulation 2006; 113:876-890. [CrossRef]

4. Elman I, Goldstein DS, Eisenhofer G, Folio J, Malhotra AK, Adler CM, Pickar D, Breier A. Mechanism of peripheral noradrenergic stimulation by clozapine. Neuropsychopharmacology 1999; 20:29-34. [CrossRef]

5. Ronaldson KJ, Fitzgerald PB, Taylor AJ, Topliss DJ, Wolfe R, McNeil JJ. Rapid clozapine dose titration and concomitant sodium valproate increase the risk of myocarditis with clozapine: A case-control study. Schizophr Res 2012; 141:173178. [CrossRef] 
6. Devarajan S, Kutcher SP, Dursun SM. Clozapine and sudden death. Lancet 2000; 355:841; author reply 843. [CrossRef]

7. Ronaldson KJ, Fitzgerald PB, Taylor AJ, Topliss DJ, McNeil JJ. Clinical course and analysis of ten fatal cases of clozapineinduced myocarditis and comparison with 66 surviving cases. Schizophr Res 2011; 128:161-165. [CrossRef]

8. Chow V, Feijo I, Trieu J, Starling J, Kritharides L. Successful rechallenge of clozapine therapy following previous clozapineinduced myocarditis confirmed on cardiac MRI. J Child Adolesc Psychopharmacol 2014; 24:99-101. [CrossRef]

9. Rosenfeld AJ, Gibbs T, Ivie R, Clarke L, Merrill DB. Successful clozapine retrial after suspected myocarditis. Am J Psychiatry 2010; 167:350-351. [CrossRef]

10. Bray A, Reid R. Successful clozapine rechallenge after acute myocarditis. Aust N Z J Psychiatry 2011; 45:90. [CrossRef]
11. Reinders J, Parsonage W, Lange D, Potter JM, Plever S. Clozapinerelated myocarditis and cardiomyopathy in an Australian metropolitan psychiatric service. Aust N Z J Psychiatry 2004; 38:915-922. [CrossRef]

12. Ronaldson KJ, Fitzgerald PB, Taylor AJ, Topliss DJ, McNeil JJ. A New Monitoring Protocol for Clozapine-Induced Myocarditis Based on an Analysis of 75 Cases and 94 Controls. Aust N Z J Psychiatry 2011; 45:458-465. [CrossRef]

13. Otsuka Y, Idemoto K, Hosoda Y, Imamura Y, Aoki T. Clozapineinduced myocarditis: follow-up for 3.5 years after successful retrial. J Gen Fam Med 2019; 20:114-117. [CrossRef]

14. Ittasakul P, Archer A, Kezman J, Atsariyasing W, Goldman MB. Rapid rechallenge with clozapine following pronounced myocarditis in a treatment-resistant schizophrenia patient. Clin Schizophr Relat Psychoses 2016; 10:120-122. [CrossRef] 